\title{
Silva, M. C.; Lima, M. L.; Sobral, J. M.; Araújo, H. \& Ribeiro, F. B. (EDS.) (2017). Desigualdades E Políticas de Género. V.N. FAMalicão: Húmus.
}

\author{
Carla Cerqueira
}

Desigualdades e políticas de género é um livro organizado por Manuel Carlos Silva, Maria Luísa Lima, José Manuel Sobral, Helena Araújo e Fernando Bessa Ribeiro, investigadoras/es portuguesas/es de renome nas Ciências Sociais, os quais provêm de disciplinas distintas - Sociologia, Psicologia, Antropologia e Ciências da Educação. A obra de cerca de 300 páginas apresenta, assim, uma pluralidade de olhares e estudos focados em realidades concretas sobre as desigualdades de género que persistem. Trata-se, portanto, de um volume centrado nos estudos de género, atualmente encarados como "um campo de grande vitalidade: nunca como hoje foi tão forte o sistema de reenvios interdisciplinares dentro da comunidade académica" (Silva \& Tavares, 2001, p. 133).

A base do livro é um projeto sobre (des)igualdades de género no trabalho e na vida familiar, desenvolvido por várias/os destas/es investigadoras/es, o qual culminou com um colóquio internacional, realizado em 2011, que teve a designação que deu origem ao título Desigualdades e Políticas de Género.

Em termos de estrutura, o livro está dividido em duas grandes partes e onze capítulos. A primeira parte congrega os contributos de oradoras/es convidadas/os do colóquio e a segunda de membros da equipa, tal como se refere no capítulo introdutório. "A desigualdade de género é antiga" (p. 9) é a frase que dá o mote para que as/os organizadoras/es do livro façam uma breve reflexão histórica para explicar a base dessa desigualdade que persiste na atualidade. Passam pelos contributos dos movimentos feministas, nas suas diversas correntes, e as conquistas alcançadas, mas não deixam de sublinhar que,
apesar da situação presente das mulheres estar longe daquela que elas viveram há algumas décadas atrás, o quadro continua a ser bem difícil. Mesmo nos países mais desenvolvidos, as mulheres têm mais dificuldades em chegar a cargos e profissões melhor remunerados; a maioria dos lares pobres é encabeçada por mulheres e, as políticas neoliberais de destruição do Estado social provocam especiais efeitos nos direitos e nas condições sociais das mulheres. Por outro lado, as forças políticas e sociais conserva- doras persistem, ora em negar, ora em reverter direitos fundamentais como o da interrupção voluntária da gravidez (p. 15).

Ainda na introdução as/os organizadoras/es ressaltam que é necessária uma análise que articule classe e género e as diversas formas de desigualdade que lhe são 
inerentes. Aliás, menciona-se que "a luta pelos direitos das mulheres é inseparável da luta, na qual elas também são parte interessada e ativa, por uma sociedade mais justa, livre e emancipada" (p. 13). Percebe-se, por isso, que a obra incorpora uma abordagem do feminismo marxista, a qual muitas vezes tem estado secundarizada ou mesmo omitida no âmbito dos estudos de género.

É também de sublinhar que a tensão entre leis e práticas está presente ao longo dos diversos capítulos, pois muitas vezes a justificação que existem garantias jurídicas e que a igualdade de género está consagrada tenta apagar outras lutas e silenciar as situações de desigualdade que persistem e inevitavelmente marcam o nosso quotidiano, tal como as investigações empíricas presentes na obra comprovam.

Diversas são as abordagens e temas que são discutidas. O livro inicia com um texto de Sara Falcão Casaca que apresenta uma análise teórica das relações de género. A autora percorre diversos paradigmas, relevando a articulação do construcionismo com alguns aspetos estruturais. Discute o papel do Estado nas relações de género, nomeadamente no campo laboral, e termina frisando que "as perspetivas têm presente o caráter histórico, dinâmico e contingencial das relações de género" (p. 42).

De seguida as investigadoras espanholas Capitolina Diaz e Sandra Moreno dão a conhecer as várias dimensões que perpassam as desigualdades de género, numa ótica intergeracional, existentes nos lares espanhóis. O estudo apresentado visa realçar algumas das mudanças que estão a ocorrer e que não são equacionadas nas estatísticas nacionais nem europeias, as quais não contemplam a diversidade de famílias existentes, aspetos relacionados com o cuidado doméstico e com as transações bancárias, entre outros (pp. 54-55).

Joanna Schouten analisa a organização do tempo no espaço doméstico, o qual continua a ser mais ocupado pelas mulheres nas tarefas de cuidado e gestão do lar (p. 74). No que concerne à introdução das tecnologias nesse domínio, e na linha de outros estudos (por exemplo, Perista, 2010; Wajcman, 2000), a investigadora sublinha que "não é a tecnologia por si que traduz mudança" (p. 73), pois o uso que se faz dela é bastante inspirado pelas normas de género.

De seguida, Aleksandra Queiroz, Manuel Carlos Silva, Ana Reis Jorge e Maria CaneIhas, apresentam uma análise sobre emprego e desemprego na União Europeia e em Portugal, em que se ressalta que a diferença entre trabalho remunerado e trabalho doméstico não remunerado demonstra uma assimetria de género em prejuízo das mulheres ( $p$. 103). O hiato entre a legislação e as práticas nas organizações é realçado, por isso neste capítulo sugere-se um reforço com vista à consagração das medidas existentes (p. 104).

A encerrar a primeira parte do livro, Ana Paula Marques apresenta um estudo sobre o potencial do empreendedorismo para as mulheres jovens, ressaltando que as soluções "para o crescimento económico e o combate ao desemprego não se esgotam no empreendedorismo tout court" (p. 127). Menciona igualmente que as mulheres diplomadas estão em situação de maior vulnerabilidade quando comparadas com os seus colegas homens e que as desigualdades de género continuam a ser visíveis nas escolhas realizadas na trajetória educativa e no mercado de trabalho. 
Na segunda parte são apresentados os principais resultados do projeto Desigualdades e Políticas de Género, desenvolvido em Portugal Continental. A iniciar, um capítulo da autoria de Manuel Carlos Silva e Helena Araújo que tem como propósito fazer a caraterização sócio-demográfica das pessoas inquiridas, na qual se destaca que um elevado número possui casa própria e encontra-se nos escalões baixos e intermédios de escolaridade, ou seja, com pouca qualificação, o que contraria a ideia da "massificação do ensino superior" (p. 157).

Segue-se um estudo empírico, apresentado por Maria Luísa Lima e José Manuel Sobral, sobre a forma como os estereótipos de género continuam a ser marcantes para estruturar as desigualdades. Neste refere-se que o sexismo benevolente é extremamente perigoso e insidioso porque desvaloriza de modo paternalista as mulheres e garante a supremacia masculina, sendo muitas vezes aceite por elas. Os autores recorrem a exemplos da atualidade em diversos contextos que demonstram precisamente que esta é "uma ideologia eficiente na manutenção dos papéis tradicionais de género" (p. 186) e que por isso "o sexismo na nossa sociedade está para durar" (p. 185).

A forma como os valores de ordem religiosa, nomeadamente católica, estão relacionados com a política e influenciam os comportamentos, estando estes associados a uma dimensão de género e de classe, é discutida por Manuel Carlos Silva e Fernando Bessa Ribeiro. Os autores concluem que as mulheres inquiridas no estudo estão mais vinculadas à crença e à prática religiosa. Além disso, há cada vez uma maior confiança em entidades não partidárias do que nos partidos políticos, aspeto este que, segundo os investigadores, "é fatal para a construção de uma agenda política progressista e emancipatória, também no campo das políticas de género" (p. 209).

Os últimos dois capítulos abordam as desigualdades no âmbito dos casamentos e divórcios. Em primeiro lugar, Ana Reis Jorge e Manuel Carlos Silva analisam os processos judiciais de divórcio e concluem que as mulheres são as mais penalizadas. Quando são elas a pedir o divórcio as motivações relacionam-se com situações de violência, de não divisão das tarefas domésticas ou de falta de contribuição monetária dos homens. Já no caso deles é a necessidade de regularização de uma situação de separação (pp. 262-263). As responsabilidades parentais e as vivências associadas às mesmas, segundo uma perspetiva de género, também são trazidas para a discussão por Ana Reis Jorge, no capítulo que encerra a obra. Ressalta-se que as normatividades tradicionais de género vivenciadas antes das ruturas parecem continuar a ser reproduzidas após o divórcio, com as mulheres muito mais associadas aos domínios do cuidado e da educação (p. 292).

Este livro permite, assim, iluminar várias desigualdades de género que, apesar de todas as mudanças verificadas, ainda permanecem bem enraizadas e que se manifestam de forma explícita ou subtil. As análises aqui apresentadas são cruciais, até porque diariamente circulam discursos que sublinham que a igualdade já existe e que há tantas políticas públicas nesse sentido que muitas lutas e reivindicações não são mais necessárias. É aquilo que Banyard (2010) apelida de "ilusão de igualdade", tão perigosa e difícil de desconstruir, sobretudo porque muitos dos sexismos são benevolentes, subtis, encapotados, como explicam no livro Maria Luísa Lima e José Manuel Sobral. Por outro lado, os sexismos estão para durar porque se verifica uma instrumentalização das questões 
de género, que entraram no mainstream e que são mais uma das apropriações da academia neoliberal. Este panorama leva a questionar: E que mudanças temos nas relações de poder, em termos estruturais e nos discursos? Muito poucas, como se demonstra nesta obra.

Já no que concerne às políticas de género, e nomeadamente às políticas públicas neste campo, esta coletânea de estudos também nos levanta muitas discussões, sobre várias áreas e com diferentes abordagens, umas mais descritivas, outras mais analíticas, mas que trazem sempre consigo uma dimensão política, de questionamento e necessidade de mudança social.

Articulando teoria e prática, as áreas abarcadas são de extrema importância. Obviamente que seria importante que a obra incorporasse uma linguagem neutra ou inclusiva de género em todos os textos e a utilização de um grafismo que possa ultrapassar os binarismos de género. O debate científico abre pistas para novas pesquisas que ficam por responder com os dados e reflexões apresentados, por isso considero que este livro é mais um contributo para a reflexão que merece (re)conhecimento.

\section{REFERÊNCIAS BiBLIOGRÁFICAS}

Banyard, K. (2010). The Equality Illusion: The Truth about Women and Men Today. Londres: Faber \& Faber.

Perista, H. (2010). Mulheres, homens e usos do tempo: Quinze anos após a Plataforma de Acção de Pequim, onde estamos, em Portugal?. Revista de Estudos Demográficos, 47, 47-64.

Silva, A. \& Tavares, T. (2001). Estudos Culturais, Estudos sobre as Mulheres e Estudos Culturais sobre as Mulheres. Ex aequo, A construção dos estudos sobre as mulheres em Portugal I, 5, 123-148.

Wajcman, J. (2000). Reflections on gender and technology studies: In what state is the art?. Social Studies of Science, 30 (3), 447-64.

\section{Nota BiográFICA}

Carla Cerqueira é doutorada em Ciências da Comunicação - especialidade de Psicologia da Comunicação pela Universidade do Minho. Atualmente é bolseira de pós-doutoramento em Ciências da Comunicação da Fundação para a Ciência e a Tecnologia (SFRH/BPD/86198/2012), com um projeto que cruza a cobertura jornalística dos temas de género com as estratégias de comunicação das ONG da área da cidadania e igualdade de género. É investigadora do Centro de Estudos de Comunicação e Sociedade (CECS) e Professora Auxiliar na Universidade Lusófona do Porto.

E-mail: carlaprec3@gmail.com

Centro de Estudos de Comunicação e Sociedade, Instituto de Ciências Sociais, Campus de Gualtar, 4710-057 Braga, Portugal

\section{* Submetido:26-05-2017 \\ * Aceite: 19-06-2017}

